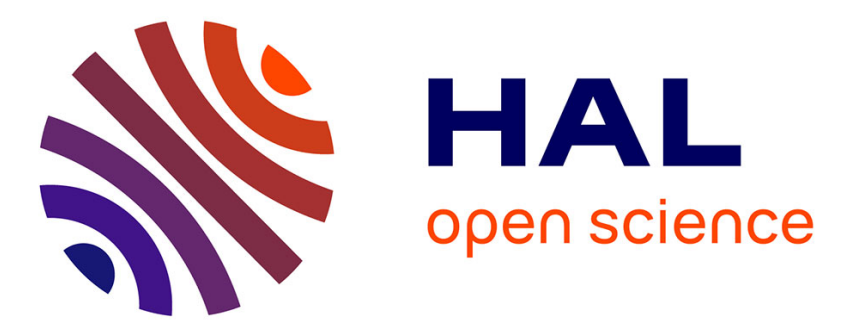

\title{
Local Degradation Mechanisms by Tarnishing of Protected Silver Mirror Layers Studied by Combined Surface Analysis
}

Emna Limam, Vincent Maurice, Antoine Seyeux, Sandrine Zanna, Lorena H Klein, Grégory Chauveau, Catherine Grezes-Besset, Isabelle Savin de Larclause, Philippe Marcus

\section{To cite this version:}

Emna Limam, Vincent Maurice, Antoine Seyeux, Sandrine Zanna, Lorena H Klein, et al.. Local Degradation Mechanisms by Tarnishing of Protected Silver Mirror Layers Studied by Combined Surface Analysis. Journal of Physical Chemistry B, 2017, 122 (2), pp.578-586. 10.1021/acs.jpcb.7b05015 . hal-02354495

\section{HAL Id: hal-02354495 \\ https://hal.science/hal-02354495}

Submitted on 7 Nov 2019

HAL is a multi-disciplinary open access archive for the deposit and dissemination of scientific research documents, whether they are published or not. The documents may come from teaching and research institutions in France or abroad, or from public or private research centers.
L'archive ouverte pluridisciplinaire HAL, est destinée au dépôt et à la diffusion de documents scientifiques de niveau recherche, publiés ou non, émanant des établissements d'enseignement et de recherche français ou étrangers, des laboratoires publics ou privés. 


\section{Local Degradation Mechanisms by Tarnishing of Protected Silver Mirror Layers Studied by Combined Surface Analysis}

Emna Limam, ${ }^{a}$ Vincent Maurice, ${ }^{a,}{ }^{*}$ Antoine Seyeux, ${ }^{a}$ Sandrine Zanna,${ }^{a}$ Lorena H. Klein,${ }^{a}$ Grégory Chauveau, ${ }^{b}$ Catherine Grèzes-Besset, ${ }^{b}$ Isabelle Savin De Larclause, ${ }^{c}$ Philippe $\operatorname{Marcus}^{a, \dagger}$

aPSL Research University, CNRS-Chimie ParisTech, Institut de Recherche de Chimie Paris, Physical Chemistry of Surfaces Group, 11 rue Pierre et Marie Curie, 75005 Paris, France

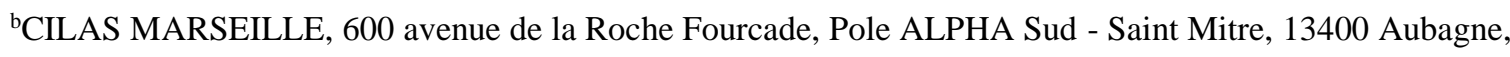
France

${ }^{\mathrm{c}}$ CNES, Sous-direction Assurance Qualité, Service Technologies, Matériaux et Procédés, 18 Avenue Édouard Belin, 31401 Toulouse, France

\footnotetext{
* Corresponding author ; email address : vincent.maurice@ chimie-paristech.fr
}

${ }^{\dagger}$ Corresponding author ; email address : philippe.marcus@chimie-paristech.fr 


\begin{abstract}
In this work, we addressed the local degradation mechanisms limiting the pre-launch environmental durability of thin-layered silver stacks for demanding space mirror applications. Local initiation and propagation of tarnishing were studied by combined surface and interface analysis on model stack samples consisting of thin silver layers supported on light-weight $\mathrm{SiC}$ substrates and protected by thin $\mathrm{SiO}_{2}$ overcoats, deposited by cathodic magnetron sputtering and submitted to accelerated aging in gaseous $\mathrm{H}_{2} \mathrm{~S}$. The results show that tarnishing is locally initiated by the formation of $\mathrm{Ag}_{2} \mathrm{~S}$ columns erupting above the stack surface. $\mathrm{Ag}_{2} \mathrm{~S}$ growth is promoted at high aspect ratio defects (surface pores) of the $\mathrm{SiC}$ substrate as a result of an imperfect protection by the $\mathrm{SiO}_{2}$ overcoat. Channels most likely connect the silver layer to its environment through the protection layer, which enables local $\mathrm{H}_{2} \mathrm{~S}$ entry and $\mathrm{Ag}_{2} \mathrm{~S}$ growth. The silver sulfide columns grow in number and size eventually leading to coalescence with increasing $\mathrm{H}_{2} \mathrm{~S}$ exposure. In more advanced stages, tarnishing slows down owing to saturation of all pre-existing imperfectly protected sites of preferential sulfidation. However, it progresses radially at the basis of the $\operatorname{Ag}_{2} \mathrm{~S}$ columns underneath the protection layer, consuming the metallic silver layer and deteriorating the protecting overcoat.
\end{abstract}




\section{Introduction}

Thanks to its unique optical properties combining high reflectivity in the visible and low emissivity in the infrared, ${ }^{1,2}$ silver is the most appropriate material for use as metallic mirrors in demanding applications, in particular for space telescopes embarked on satellites assigned to earth observation missions. Nevertheless, owing to the susceptibility of silver to atmospheric corrosion, the use of silver mirror layers in space telescopes raises the issue of long-term environmental durability on earth after satellite assembly and before launching.

The degradation of silver caused by atmospheric corrosion has been extensively studied but discrepancies still remain on the degradation mechanisms and the major resulting corrosion products, which is in part due to the variety in studied silver samples and environmental conditions. ${ }^{3-7}$ Results obtained after natural and accelerated aging may differ. ${ }^{8-}$ 10 Moreover, results obtained in the field depend on environmental conditions varying with geographic locations, seasons and surrounding installations and activities. ${ }^{11-15}$

The major corrosion products of the atmospheric corrosion of silver are silver sulfide $\left(\mathrm{Ag}_{2} \mathrm{~S}\right)$ and silver chloride $(\mathrm{AgCl})$ though silver oxide $\left(\mathrm{Ag}_{2} \mathrm{O}\right)$ and silver sulfate $\left(\mathrm{Ag}_{2} \mathrm{SO}_{4}\right)$ have been also found. ${ }^{2,3,6} \mathrm{Ag}_{2} \mathrm{~S}$ is usually found predominant in indoor atmospheres. ${ }^{14,16-22}$ Silver sulfide is the product of the corrosion of silver by organosulfur compounds or $\mathrm{H}_{2} \mathrm{~S}$ contaminants. For $\mathrm{H}_{2} \mathrm{~S}$, a concentration as low as $0.2 \mathrm{ppb}$ has been shown to be sufficient to initiate silver sulfidation, ${ }^{23}$ which makes $\mathrm{H}_{2} \mathrm{~S}$ the most used gas to study silver gaseous sulfidation in laboratory. . $^{3,24-27}$

Silver sulfide is a black corrosion product responsible for the loss of silver brilliance. It is thus called tarnish and its formation tarnishing. This phenomenon is particularly damaging for the optical properties of space mirrors. Dielectric layers consisting of $\mathrm{SiO}_{2},{ }^{24}$ $\mathrm{Al}_{2} \mathrm{O}_{3},{ }^{28,29} \mathrm{Si}_{3} \mathrm{~N}_{4},{ }^{30,31}$ or $\mathrm{SiN}_{\mathrm{x}}{ }^{32-34}$ have been used as overcoats for confinement of the silver layer and protection from environmental degradation by tarnishing. Most of the degradation 
studies performed on space silver-based mirrors addressed the efficiency of the protection layer and the effect of aging on the optical properties. ${ }^{25,29,34-37}$ Few studies were found to discuss their degradation mechanisms. ${ }^{38-40}$

Here we bring new physical insight on the local tarnishing mechanisms of model stack samples of space mirrors grown by cathodic magnetron sputtering and consisting of thin silver layers protected by $\mathrm{SiO}_{2}$ layers and deposited on $\mathrm{SiC}$, a substrate already in use in all $\mathrm{SiC}$ space telescopes assigned to scientific missions and earth observation missions. To our knowledge, no studies of the degradation mechanism on this substrate have been reported. Time-of Flight Secondary Ion Mass Spectrometry (ToF-SIMS), X-ray Photoelectron Spectroscopy (XPS) and Atomic Force Microscopy (AFM) analysis was performed before and after accelerated aging in gaseous $\mathrm{H}_{2} \mathrm{~S}$ selected as most corrosive atmospheric agent. We show that the initiation of tarnishing is local and triggered by the presence of high aspect ratio defect sites (i.e. surface pores) of the $\mathrm{SiC}$ substrate imperfectly sealed by the protection layer, and that its propagation in later stages proceeds radially underneath the protection layer.

\section{Experimental}

\section{Sample preparation and sulfidation}

Silicon carbide was used as substrate material because of the increasing interest for all-SiC telescopes of lighter weight than with glass or quartz substrates. SiC Boostec $®$ samples $\left(10 \times 10 \times 1.5 \mathrm{~mm}^{3}\right)$ were purchased from Mersen. The substrates used in the present work had an optical surface finish with rms roughness of $4.4 \mathrm{~nm}$.

The multilayer stacks including silver and dielectric protection were deposited by CILAS Marseille using cathodic magnetron sputtering. The PACA2M deposition platform designed to produce large optical components was used. ${ }^{41-43}$ This platform is installed in 
clean room and equipped with 5 magnetron sources (enabling to use up to 7 cathodes) that can be operated in DC (Direct Current), MF (Mid Frequency) or RF (Radio Frequency) mode and whose dimensions enable to deposit uniform metallic and/or dielectric multilayers on optical components up to $2 \times 2 \times 0.4 \mathrm{~m}^{3}$ in size and $1500 \mathrm{~kg}$ in weight. It is also equipped with an in situ broadband optical monitoring of the optical performance. The stacks prepared for the present study consisted in (i) an adhesion layer of metallic nickel and chromium, about $10 \mathrm{~nm}$ thick, (ii) a silver layer, 100 to $200 \mathrm{~nm}$ thick, (iii) an adhesion interface layer, and (iv) a dielectric protection layer of silicon dioxide, 100 to $200 \mathrm{~nm}$ thick. Prior to deposition, the targets surfaces were pretreated by Ar sputtering in order to minimize their surface contamination. Once deposited the stack samples were enclosed in membrane boxes and shipped to CNRS-Chimie ParisTech for surface and interface analysis and accelerated aging.

Accelerated atmospheric aging was performed in gaseous $\mathrm{H}_{2} \mathrm{~S}$ selected as most corrosive indoor atmospheric agent for silver. The as-received stacks were installed into a quartz tube mounted into a setup dedicated to thermal treatments under reactive gases. ${ }^{44-47}$ The tube was first pumped to secondary vacuum in the $10^{-5}$ mbar range, and then filled with $\mathrm{H}_{2} \mathrm{~S}$ gas (5N purity, Air Liquide) at pressures from high $10^{-5}$ mbar range to 1000 mbar. The results reported hereafter are for accelerated aging tests performed at 1000 mbar and $75^{\circ} \mathrm{C}$. Thermal sulfidation was performed using a tubular oven during 24, 48 and $96 \mathrm{~h}$. It was stopped by pumping back the system to secondary vacuum and simultaneously cooling down by quenching the quartz tube with iced water. The sulfurized samples were then kept under vacuum until transfer through air for surface analysis.

\section{Surface and interface analysis}

XPS analysis was performed with a VG ESCALAB 250 spectrometer at an operating pressure of about $10^{-9}$ mbar. An $\mathrm{Al} \mathrm{K \alpha}$ monochromatized radiation $(\mathrm{h} v=1486.6 \mathrm{eV})$ was employed as X-ray source. The spectrometer was calibrated against the reference binding 
energies (BE) of clean $\mathrm{Cu}(932.6 \mathrm{eV}), \mathrm{Ag}(368.2 \mathrm{eV})$ and $\mathrm{Au}(84 \mathrm{eV})$ samples. For all analyses, the take-off angle was $90^{\circ}$. Survey spectra were recorded with a pass energy of $100 \mathrm{eV}$, and high resolution spectra of the C 1s, O 1s, Si 2p, S 2p and Ag 3d core level regions were collected with a pass energy of $20 \mathrm{eV}$. Data processing (peak fitting and decomposition) was performed with the Advantage software provided by Thermo Electron, using a Shirley-type background and Gaussian/Lorentzian peak shapes combined at a fixed ratio of 70/30. BEs of the component peaks were corrected with reference to the carbon peak for $-\mathrm{CH}_{2}-\mathrm{CH}_{2}$ - bonds set at $285.0 \mathrm{eV}$. Atomic concentration ratios were calculated from the intensities of the component peak assuming a homogeneous semi-infinite material and using the calibrated transmission factors of the spectrometer, Scofield photoionisation cross sections and values of the photoelectron attenuation lengths calculated using the method of Tanuma et al. $^{48}$

ToF-SIMS analysis was performed with an IonTof 5 spectrometer operating at a pressure of approximately $10^{-9}$ mbar. Elemental depth profile analysis and imaging were both conducted in negative secondary ion mode. Depth profiling analysis was performed with a pulsed $25 \mathrm{keV} \mathrm{Bi}^{+}$primary ion source delivering a target current of $1.2 \mathrm{pA}$ over a $100 \times 100 \mu \mathrm{m}^{2}$ area and interlaced with sputtering performed with a $2 \mathrm{keV} \mathrm{Cs}^{+}$ion gun delivering $100 \mathrm{nA}$ of target current over a $300 \times 300 \mu \mathrm{m}^{2}$ area. These conditions were reproduced for all samples allowing direct comparison of the relative secondary ion intensities. For chemical imaging, a pulsed $25 \mathrm{keV} \mathrm{Bi}^{+}$primary ion source was employed, delivering $0.15 \mathrm{pA}$ of current over a $100 \times 100 \mu \mathrm{m}^{2}$ area analyzed with a resolution of about $150 \mathrm{~nm}$. For in-depth chemical imaging, the sputtering gun was used in the same conditions as for depth profiling for accessing different levels in the supported stack based on sputtering time determined from previous depth profile analysis. Data acquisition and post-processing analyses were performed with the Ion-Spec software. 
AFM imaging was performed in intermittent contact (tapping ${ }^{\circledR}$ ) mode in air, using an Agilent 5500 microscope. A silicon cantilever with a resonance frequency in the range 200$400 \mathrm{kHz}$ and a force constant in the range $25-75 \mathrm{Nm}^{-1}$ was employed. The silicon tip had a nominal radius $<10 \mathrm{~nm}$.

\section{Results and Discussion}

\section{SiC substrate and as-received supported stacks}

AFM topographic images of the bare $\mathrm{SiC}$ Boostec ${ }^{\circledR}$ substrate are shown in Figure 1(a,b,c). They evidence surface porosity confirmed by the provider as resulting from the SiC material production process. The pores have lateral dimensions ranging from $\sim 0.5$ to $\sim 6 \mu \mathrm{m}$ at the surface level. Their depth measured by AFM ranges from $\sim 0.05$ to $\sim 0.4 \mu \mathrm{m}$. Their density is $\sim 1.6 \times 10^{6} \mathrm{~cm}^{-2}$ as measured from $50 \times 50 \mu \mathrm{m}^{2}$ scans. In between the pores the topography consists of dispersed features appearing grain-like and possibly consisting of contamination products (Figure 1(b)). Their lateral dimensions are 200-300 $\mathrm{nm}$ and they protrude from 4 to $20 \mathrm{~nm}$ above the base surface level. Some of these features are locally aggregated. The measured rms roughness is $3.7 \mathrm{~nm}$, in good agreement with the nominal value $(4.4 \mathrm{~nm})$. Inside the pores, the same grain-like morphology is measured. In some cases (Figure 1(c)), this morphology appears inhomogeneous and the pore bottom appears irregular as if the pores were partially filled by contamination products.

After deposition of the silver mirror layer (Figure 1(d,e,f), surface porosity is still observed. The pores have similar shape, dimensions and density as before deposition, showing that they are not filled by the silver layer. Both outside (Figure 1(e)) and inside (Figure 1(f)) the pores, a finer granular morphology is observed. The grains have lateral dimensions of $100-150 \mathrm{~nm}$, significantly smaller than those measured on the bare substrate. Outside the pores, this granular morphology is compact and homogeneously covers the 
surface with an outer surface level protruding locally about $10 \mathrm{~nm}$ above the main surface level. Obviously, this finer granular morphology, different from that of the bare substrate surface, is that of the deposited silver layer. Examination inside the pores reveals that they are partially filled by the granular morphology and thus by the silver layer (Figure 1(f)). The pores remain unfilled after deposition of the protection oxide layer as shown further on.

Figure 2 shows ToF-SIMS elemental depth profiles of the as-received complete $\mathrm{SiC} / \mathrm{Ag} / \mathrm{SiO}_{2}$ stack. The intensity of the selected $\mathrm{SiO}_{2}^{-}, \mathrm{SiO}^{-}$, "Int"-, $\mathrm{Ag}_{2}^{-}, \mathrm{Ag}^{-}, \mathrm{NiCr}^{-}$and $\mathrm{SiC}^{-}$ ions are plotted on a logarithmic scale versus sputtering time. Starting from the outer surface, the intensity profiles of these ions define five regions, all marked and corresponding successively to: the protection layer $\left(\mathrm{SiO}_{2}^{-}, \mathrm{SiO}^{-}\right)$, the interfacial layer $\mathrm{I}_{\mathrm{a}}$ ("Int"- ions), the silver layer $\left(\mathrm{Ag}_{2}{ }^{-}, \mathrm{Ag}^{-}\right)$, the adhesion layer $\mathrm{Ib}_{\mathrm{b}}\left(\mathrm{NiCr}^{-}\right)$and the $\mathrm{SiC}$ substrate $\left(\mathrm{SiC}^{-}\right)$. In the protection layer region both the $\mathrm{SiO}_{2}^{-}$and $\mathrm{SiO}^{-}$ions profiles exhibit plateaus of increasing intensity with in-depth progress toward the $\mathrm{I}_{\mathrm{a}}$ interface, suggesting a density of the $\mathrm{SiO}_{2}$ layer decreasing with on-going deposition from the $\mathrm{I}_{\mathrm{a}}$ interface. One also notices that the "Int"-, $\mathrm{Ag}^{-}$ and $\mathrm{SiC}^{-}$ions are detected in the protection layer region. The presence of $\mathrm{Ag}$ in a protective oxide layer $\left(\mathrm{TiO}_{2}\right)$ has previously been observed and attributed to photo-enhanced diffusion during deposition promoted by oxygen adsorption on silver. ${ }^{49}$ The intensity of the $\mathrm{SiC}^{-}$ions in the protection layer region is relatively high. Although some carbon contamination during deposition and silicium-carbon combination during analysis cannot be fully excluded, it appears consistent with the AFM observations that show that locally, in the $\mathrm{SiC}$ surface pores, the silver layer is not fully covering. Thus not only the $\mathrm{SiC}^{-}$ions but also the "Int"- and $\mathrm{Ag}^{-}$ ions that are detected in the protection region indicate that the whole stack is locally imperfect and also not fully covering the $\mathrm{SiC}$ substrate.

In the $\mathrm{I}_{\mathrm{a}}$ interfacial region, the intensity maxima of the $\mathrm{Ag}_{2}{ }^{-}$and $\mathrm{Ag}^{-}$ions coincide with the maximum of the "Int"- ions. This is consistent with the formation of a discontinuous $I_{a}$ 
interface layer deposited as islands, ${ }^{32,50}$ possibly indicative of silver diffusion during deposition, ${ }^{49}$ and that has been discussed as promoting the nucleation of a dense protection layer of decreased permeability. ${ }^{35,39,51}$ The oxidation of silver in this interlayer region has been advanced in previous studies. ${ }^{49,52}$ The similar profiles of the $\mathrm{Ag}_{2}{ }^{-}$and $\mathrm{Ag}^{-}$ions in the present ToF-SIMS data indicate that silver is, at least in part, in the metallic state in this region. In the $\mathrm{Ag}$ layer region, the $\mathrm{Ag}_{2}{ }^{-}$and $\mathrm{Ag}^{-}$ions profiles are parallel and display a plateau which is consistent with the formation of a continuous metallic layer. All other ions drop down in intensity also as expected, except for the $\mathrm{SiC}^{-}$ions that increase. Again, this is consistent with the presence of partially filled substrate surface pores. In the $\mathrm{I}_{\mathrm{b}} \mathrm{NiCr}$ region, the $\mathrm{Ag}_{2}{ }^{-}$and $\mathrm{Ag}^{-}$ions drop down in intensity as expected, which coincides with a peak in the $\mathrm{NiCr}^{-}$ions profile. The $\mathrm{SiC}^{-}$ions further increase in intensity until reaching a plateau in the $\mathrm{SiC}$ substrate region. The relatively high intensity of the $\mathrm{Ag}^{-}$ions in the substrate region and its decrease with in-depth progress is consistent with the presence of surface pores with a depth reaching hundreds of nanometers as measured by AFM and partially filled with silver. In the $\mathrm{Ib}_{\mathrm{b}} \mathrm{NiCr}$ region, peaks are observed in the $\mathrm{SiO}_{2}^{-}$and $\mathrm{SiO}^{-}$ions profiles. They are indicative of silicon oxide contamination at the substrate surface. Similar residual contamination of the substrate surface by oxides has been also reported in the case of alumina, chromia or tantala protection layers grown by atomic layer deposition or filtered cathodic arc deposition on low-alloy steel, ${ }^{53-55}$ stainless steel ${ }^{56}$ and copper ${ }^{57,58}$ substrates. One notices that, like for the $\mathrm{Ag}^{-}$ions, the relatively high intensity of the $\mathrm{SiO}_{2}^{-}$ions in the substrate region is consistent with surface oxidation of the substrate surface pores.

ToF-SIMS analysis was also indicative of trace contamination by carbon, oxygen, nitrogen and chlorine during deposition and also following exposure to ambient air, suggesting that the stacks are permeable to the environment. Although contamination has been shown to impact the optical properties of protected silver mirrors, ${ }^{52,59-61}$ these results are 
not discussed in details here since not directly relevant to the resistance of the protected mirrors to tarnishing. Sulfur contamination was also observed which is discussed hereafter.

\section{Formation of $\mathrm{Ag}_{2} \mathrm{~S}$ columns}

Figure 3 shows the XP spectra of $\mathrm{Ag} 3 \mathrm{~d}$ and $\mathrm{S} 2 \mathrm{p}$ core level regions for complete $\mathrm{SiC} / \mathrm{Ag} / \mathrm{SiO}_{2}$ stacks before $(0 \mathrm{~h})$ and after accelerated aging in $\mathrm{H}_{2} \mathrm{~S}$ for 24,48 and $96 \mathrm{~h}$. For all samples, the recorded XP C 1s spectra could be fitted with one major component peak set at $285 \mathrm{eV}$ and assigned to $-\mathrm{CH}_{2}-\mathrm{CH}_{2}$ - bonded carbon, and one minor component peak at 287.4 $\pm 0.1 \mathrm{eV}$ assigned to $\mathrm{C}=\mathrm{O}$ and/or $\mathrm{O}-\mathrm{C}=\mathrm{O}$ bonded carbon. This is typical of surface organic contamination on oxide thin films exposed to ambient air. ${ }^{44,47,54}$ Both the XP Si $2 p$ and $\mathrm{O} 1 \mathrm{~s}$ spectra (not shown) could be fitted with one single component peak at 103.2 \pm 0.1 and $533.1 \pm 0.1 \mathrm{eV}$, respectively, as typical for silicon dioxide. ${ }^{62,63}$ The $\mathrm{O} / \mathrm{Si}$ atomic ratio calculated from the intensity ratio of these component peaks was $1.9 \pm 0.2$, in agreement with the $\mathrm{SiO}_{2}$ stoichiometry. This ratio was unchanged after sulfidation of the stacks.

The XP Ag 3d region shows two peaks assigned to the $3 d_{5 / 2}-3 d_{3 / 2}$ spin orbit doublet (Figure 3). Prior to sulfidation $(0 \mathrm{~h})$, the doublet has quite low intensity and is measured at 369.9-376.1 eV, i.e. at higher $\mathrm{BE}$ than measured for unprotected mirror samples (368.6$374.6 \mathrm{eV}$ ). We assign this doublet to silver present at the surface of the stack but subject to a charging effect decreasing the kinetic energy (i.e. increasing the BE) of the emitted photoelectrons because of the low conductivity of the $\mathrm{SiO}_{2}$ dielectric layer. The $\mathrm{Ag} /(\mathrm{Si}+\mathrm{O})$ atomic ratio calculated from the component peaks intensities is $2 \times 10^{-3}$. Both this low value and the charging effect are indicative of trace silver contamination occurring after deposition of the $\mathrm{SiO}_{2}$ protection layer. ToF-SIMS confirmed that silver surface contamination could be suppressed by sputtering the $\mathrm{SiO}_{2}$ extreme surface. The $\mathrm{S} 2 \mathrm{p}$ region shows no peak prior to sulfidation (Figure 3), showing that the trace amount contamination by sulfur detected by ToF-SIMS (and discussed below) is below the detection limit of XPS. 
After accelerated aging in $\mathrm{H}_{2} \mathrm{~S}$, the XP $\mathrm{Ag} 3 \mathrm{~d}_{5 / 2}-3 \mathrm{~d}_{3 / 2}$ doublets are markedly more intense and positioned at lower binding energy, $367.8 \pm 0.1$ and $373.8 \pm 0.1 \mathrm{eV}$, respectively. The value of the Auger parameter $\alpha^{\prime}$ is $724.8 \pm 0.2 \mathrm{eV}$ as calculated from the kinetic energy of the $\mathrm{Ag} \mathrm{M}_{4} \mathrm{NN}$ Auger transition (1129.6 $\pm 0.1 \mathrm{eV}$ ) and binding energy of the $\mathrm{Ag} 3 \mathrm{~d}_{5 / 2}$ core level, in good agreement with values reported for $\mathrm{Ag}_{2} \mathrm{~S}$. ${ }^{64-67}$ The formation of $\mathrm{Ag}_{2} \mathrm{~S}$ is also supported by the $S 2 p$ region that shows $2 p_{3 / 2}-2 p_{1 / 2}$ spin orbit doublets at $160.7 \pm 0.1$ and 161.9 $\pm 0.1 \mathrm{eV}$, respectively, and characteristic for silver sulfide. ${ }^{64,66,68-71}$ Combined with the fact that no charging effect is measured anymore already after $24 \mathrm{~h}$ sulfidation, these data point to formation of $\mathrm{Ag}_{2} \mathrm{~S}$ at the surface of the dielectric $\mathrm{SiO}_{2}$ layer but electrically connected to the conductive silver layer of the stack through the protection layer so that there is no charging during photoelectron emission. The $\mathrm{Ag} /(\mathrm{Si}+\mathrm{O})$ atomic ratio calculated from the component peak intensities is $0.5 \times 10^{-2}, 1.1 \times 10^{-2}$ and $1.8 \times 10^{-2}$ after 24,48 and $96 \mathrm{~h}$, respectively, increasing up to one order of magnitude higher than before sulfidation. This is consistent with the formation of $\mathrm{Ag}_{2} \mathrm{~S}$ columns from the silver layer and increasingly emerging at the surface of the protected mirrors.

\section{Local initiation of tarnishing at substrate surface pores}

Figure 4 shows AFM topographic images of complete $\mathrm{SiC} / \mathrm{Ag} / \mathrm{SiO}_{2}$ stacks prior to and after $24 \mathrm{~h}$ accelerated aging in $\mathrm{H}_{2} \mathrm{~S}$. Prior to sulfidation (Figure 4(a)), the surface pores of the SiC substrate are still observed with similar lateral dimension (from $\sim 0.5$ to $\sim 3 \mu \mathrm{m}$ ), depth (reaching $\sim 0.4 \mu \mathrm{m})$ and density $\left(\sim 1.6 \times 10^{6} \mathrm{~cm}^{-2}\right)$ than on the bare substrate, showing that they remain unfilled by the deposited stack. In between the pores, a compact and granular morphology of the $\mathrm{SiO}_{2}$ protection layer surface is observed with grains having lateral dimensions of $80-150 \mathrm{~nm}$, and some grain aggregates protruding locally about $20 \mathrm{~nm}$ above the main surface level. 
After $24 \mathrm{~h}$ sulfidation (Figure 4(b)), most of the surface pores of the substrate can no longer be identified. Instead, local protruding features are observed with a height ranging from $\sim 0.1$ to $\sim 1 \mu \mathrm{m}$ above the surface level of the protection layer, and with lateral dimensions ranging from $\sim 0.4$ to $\sim 6 \mu \mathrm{m}$, similar to those measured for the substrate surface pores. This confirms that, upon accelerated aging in $\mathrm{H}_{2} \mathrm{~S}$, sulfide columns, consisting of $\mathrm{Ag}_{2} \mathrm{~S}$ as shown by XPS, have grown from the silver layer and through the oxide protection layer to emerge locally above the protection layer. The density of these sulfide columns is $\sim 1.4 \times 10^{6} \mathrm{~cm}^{-2}$, which is similar to that of the substrate surface pores and thus indicative of the growth of the sulfide spots from the surface pores. Thus it is shown that sulfidation occurs preferentially at the surface pores of the substrate where the protection layer would be imperfect and locally permeable with channels connecting the outer $\mathrm{SiO}_{2}$ surface to the silver layer underneath, and enabling $\mathrm{H}_{2} \mathrm{~S}$ ingress and $\mathrm{Ag}_{2} \mathrm{~S}$ growth up to eruption above the stack surface. The AFM image in Figure 4(c) confirms that sulfidation is preferentially initiated at the substrate surface pores. In addition, it shows that the sulfide spots initially grow at the periphery of the pores which can be assigned to the imperfect sealing of these high aspect ratio sites by the $\mathrm{SiO}_{2}$ protection layer.

Figure 5 shows ToF-SIMS elemental images $\left(100 \times 100 \mu \mathrm{m}^{2}\right)$ of the surface of the complete $\mathrm{SiC} / \mathrm{Ag} / \mathrm{SiO}_{2}$ stack after 24, 48 and $96 \mathrm{~h}$ accelerated aging in $\mathrm{H}_{2} \mathrm{~S}$. The images were acquired after slight sputtering of the surface so as to remove the organic carbon contamination from exposure to ambient air and the residual Ag surface contamination discussed above. It confirms that sulfidation is local and dispersed ( $\mathrm{S}^{-}$images) and coincides with the presence of defects in the protection oxide layer $\left(\mathrm{O}^{-}\right.$and $\mathrm{O}^{-}+\mathrm{S}^{-}$images $)$. Analysis of the $\mathrm{S}^{-}$images shows that, with increasing $\mathrm{H}_{2} \mathrm{~S}$ exposure, the sulfide spots (i.e. columns) first markedly increase in density and average size, from $\sim 0.1 \times 10^{6}$ to $\sim 0.6 \times 10^{6} \mathrm{~cm}^{-2}$ and from 2 to $5.8 \mu \mathrm{m}^{2}$, respectively, as calculated after 24 and $48 \mathrm{~h}$ for sulfide spots of at least $3 \times 3$ square 
pixels $\left(1.37 \mu \mathrm{m}^{2}\right)$. After $96 \mathrm{~h}$, density and average size are $\sim 0.6 \times 10^{6} \mathrm{~cm}^{-2}$ and $6.4 \mu \mathrm{m}^{2}$, respectively, indicating the slower progress of tarnishing. This observation of a rapid increase in density and size of sulfide spots during the first two days followed by near stabilization has also been reported for unprotected silver layers deposited under vacuum and exposed to ambient air for up to 41 days, ${ }^{72}$ showing the relevance of our accelerated aging conditions for protected stacks. Our data also show coalescence to form enlarged sulfide spots (as marked in the $96 \mathrm{~h} \mathrm{~S}^{-}$image) at this more advanced stage, like previously reported for unprotected silver. ${ }^{5}$ It has to be noted that in our case the density of sulfide spots measured by ToF-SIMS is systematically lower than the density of surface pores measured by AFM, and shown above to be nearly all sulfurized after $24 \mathrm{~h}$. This is assigned to the lower space resolution of ToFSIMS imaging, unable to detect the smallest emerging sulfide columns and thus only partially accounting for the distribution of the sulfide spots in particular after $24 \mathrm{~h}$ sulfidation when they are smaller.

Analysis of the ToF-SIMS $\mathrm{O}^{-}$images reveals that the defects of the protection layer are markedly larger than the sulfide spots but that, unlike the sulfide spots, they still markedly enlarge after $48 \mathrm{~h}$ sulfidation. Their average size is $5.3,14.5$ and $28.7 \mu \mathrm{m}^{2}$ after 24,48 and $96 \mathrm{~h}$ sulfidation, respectively, as calculated for defects of at least $3 \times 3$ square pixels $\left(1.37 \mu \mathrm{m}^{2}\right)$. The geometry of the ToF-SIMS analysis with primary ions impinging the surface at a $45^{\circ}$ angle from normal can be expected to cause shadowing if the sulfide columns protrude from the surface level as shown by AFM. However, shadowing should only appear on the right side of the emerging sulfide columns since the primary ions arrive from the left side. Examination of the $\mathrm{O}^{-}+\mathrm{S}^{-}$images reveals that uncolored (black) ledges surround the sulfide spots in agreement with the larger size of the defects of the protection layer. After $48 \mathrm{~h}$ sulfidation, one observes a preferential enlargement of these ledges on the right side of the sulfide spots, which is consistent with shadowing caused by protruding sulfide columns. 
However, after $96 \mathrm{~h}$ sulfidation, this preferential orientation is no longer observed. Shadowing can thus no longer be advanced to explain the off-center positions of the sulfide spots inside the protection layer defects. Our explanation for this further enlargement of the protection layer defects and their off-center positioning is that the protection layer is deteriorated in the immediate vicinity of the sulfide columns at this stage. This implies that, at this more advanced stage, sulfidation progresses radially in the silver layer underneath the protection layer which is further discussed below.

\section{Sub-protection local progress of tarnishing}

Figure 6 shows the ToF-SIMS depth profiles of the $\mathrm{SiO}^{-}, \mathrm{AgS}^{-}$and minor isotope ${ }^{34} \mathrm{~S}^{-}$ ions for complete $\mathrm{SiC} / \mathrm{Ag} / \mathrm{SiO}_{2}$ stacks prior to $(0 \mathrm{~h})$ and after 24,48 and $96 \mathrm{~h}$ accelerated aging in $\mathrm{H}_{2} \mathrm{~S}$. The interfaces are marked for the 24 and $48 \mathrm{~h}$ samples. Their variation reflects some variation of the as received complete multilayer stacks, mostly of the protection layer thickness. Prior to sulfidation $(0 \mathrm{~h})$, the $\mathrm{SiO}^{-}$ions profile is identical to that plotted in Figure 2. Its peak in the $\mathrm{I}_{\mathrm{b}} \mathrm{NiCr}$ layer region has been assigned to residual surface oxidation of the substrate prior to deposition of the stack. A peak is also measured in the ${ }^{34} \mathrm{~S}^{-}$ions profile in the $\mathrm{I}_{\mathrm{b}} \mathrm{NiCr}$ layer region, which is also indicative of surface residual contamination of the substrate by sulfur, most likely from ambient air. The low intensity of the ${ }^{34} \mathrm{~S}^{-}$ions in the protection layer region is consistent with the uncomplete filling of the substrate surface pores by the deposited stack, as proposed for the $\mathrm{SiC}^{-}$ions measured in the protection layer region (Figure 2). The peak of the ${ }^{34} \mathrm{~S}^{-}$ions profile observed at the outer surface of the stack is indicative of sulfur contamination from storage in air after the stack deposition. The $\mathrm{AgS}^{-}$ions

profile (Figure 6) has quite low intensity and peaks concomitantly with the ${ }^{34} \mathrm{~S}^{-}$(Figure 6) and/or $\mathrm{Ag}^{-}$ions profiles (Figure 2). It is primarily assigned to the sulfidation of the silver layer exposed by the defects of the protection layer and occurring upon storage in air. The combination of silver and sulfur secondary particles during analysis cannot be excluded. 
After $24 \mathrm{~h}$ sulfidation, the $\mathrm{SiO}^{-}$ions profile is quite similar to that before sulfidation indicating no marked degradation of the structure of the stack. However, both the ${ }^{34} \mathrm{~S}^{-}$and $\mathrm{AgS}^{-}$ions profiles markedly increase in intensity in all regions of the stack and peak in the silver layer region. This is consistent with the penetration of sulfur through an imperfect $\mathrm{SiO}_{2}$ barrier layer down to the silver layer and growth of $\mathrm{Ag}_{2} \mathrm{~S}$ columns through the barrier layer up to emergence at the stack surface as concluded above. The ${ }^{34} \mathrm{~S}^{-}$and $\mathrm{AgS}^{-}$ions profiles also increase in intensity in the substrate region which is also indicative of the sulfidation of the silver deposited in the surface pores of the $\mathrm{SiC}$ substrate. One notices that, in this substrate region, the $\mathrm{AgS}^{-}$ions signal decreases more rapidly in intensity than the ${ }^{34} \mathrm{~S}^{-}$ions signal, suggesting that $\mathrm{Ag}_{2} \mathrm{~S}$ does not form in all substrate pores where sulfur penetrates. This could be due to the absence of deposited silver in some non-reacting $\mathrm{SiC}$ surface pores. $\mathrm{NiS}^{-}$and $\mathrm{CrS}^{-}$ions profiles (not shown) suggests that the sulfidation of the interfacial layer $\mathrm{Ib}$ in the surface pore where silver is absent.

After $48 \mathrm{~h}$ sulfidation, the ${ }^{34} \mathrm{~S}^{-}$and $\mathrm{AgS}^{-}$ions profiles further increase in intensity in all regions of the stack. The increase observed in the protection layer region is consistent with the growth of the sulfide spots revealed by ToF-SIMS imaging of the stack surface and with the intensity increase of the $\mathrm{Ag} 3 \mathrm{~d}$ and $\mathrm{S} 2 \mathrm{p}$ core level signals measured by XPS. The peak measured in the silver layer region is indicative of the lateral growth of silver sulfide underneath the protection layer. The $\mathrm{SiO}^{-}$ions profile is markedly modified in the silver layer and $\mathrm{I}_{\mathrm{b}} \mathrm{NiCr}$ layer regions but not in the protection layer and interfacial $\mathrm{I}_{\mathrm{a}}$ regions, confirming substantial modifications of the stack structure underneath the protection layer. The substantial modifications of the silver layer by growth of silver sulfide likely also roughens the $\mathrm{SiC}$ surface since all ${ }^{34} \mathrm{~S}^{-}, \mathrm{AgS}^{-}$and $\mathrm{SiO}^{-}$ions profiles increase in intensity in the substrate region. After $96 \mathrm{~h}$ sulfidation, the ${ }^{34} \mathrm{~S}^{-}$and $\mathrm{AgS}^{-}$ions profiles remain nearly unchanged in the protection layer region indicating no pronounced further growth of sulfidation in the outer 
part of the stack in agreement with the ToF-SIMS imaging data. However, some increase is still observed in the silver layer region and at the substrate surface indicating that local tarnishing has not reached saturation and propagates underneath the protection layer.

In order to confirm that sulfidation of the silver layer progresses laterally underneath the protection layer, we have performed ToF-SIMS analysis at different depths of the deposited stack by combining imaging with depth profiling for the $96 \mathrm{~h}$ sample. The results are presented in Figure 7 that displays superimposed $\mathrm{O}^{-}+\mathrm{S}^{-}+\mathrm{Ag}^{-}$ions images obtained at the stack extreme surface, in the $\mathrm{SiO}_{2}$ protection layer region and in the silver layer region. The $\mathrm{O}^{-}, \mathrm{S}^{-}$and $\mathrm{Ag}^{-}$ions images are coded in green, red and blue, respectively (color online). The sulfide spots appear in purple (red and blue mix). At the stack surface (Figure 7(a)), the positions of the sulfide spots match those of the defects (appearing black) in the green-coded protection layer. Black ledges surround off-centered sulfide spots in agreement with the data presented in Figure 5. The average size of the sulfide spots and protection layer defects is 12.2 and $23.9 \mu \mathrm{m}^{2}$, respectively, as calculated from the $\mathrm{S}^{-}$and $\mathrm{O}^{-}$ions images for items of at least $3 \times 3$ square pixels $\left(0.34 \mu \mathrm{m}^{2}\right)$.

In the protection layer region (Figure $7(b)$ ), the sulfide spots have a similar size $\left(11.7 \mu \mathrm{m}^{2}\right)$ whereas the protection layer defects markedly shrink $\left(15.1 \mu \mathrm{m}^{2}\right)$ reducing the width of the black ledges. This suggests the deterioration of the stack around the silver sulfide columns with a loss of protection material more pronounced at the extreme surface of the stack than underneath in the protection layer region, as pictured in Figure 7(a). In the silver layer region (Figure 7(c)), no lack of silver is observed surrounding the sulfide spots. This absence of voiding in the silver layer is in contrast with that observed around metallic silver agglomerates formed underneath an intact $\mathrm{SiN}_{\mathrm{x}}$ protection layer after accelerated environmental aging in conditions where no silver corrosion products erupting above the protection layer were formed. ${ }^{40}$ Instead of voiding, enlargement of the silver sulfide spots 
(average size of $254.6 \mu \mathrm{m}^{2}$ ) is observed in our case, confirming their radial growth in the metallic silver layer underneath the protection layer. It is proposed that the loss of the oxide protection material around the sulfide columns is caused by the volume expansion resulting from silver sulfide formation from metallic silver, with a Pilling-Bedworth ratio of 1.65 as calculated from the molar volume of $\mathrm{Ag}_{2} \mathrm{~S}\left(33.82 \mathrm{~cm}^{3}\right)$ and $\mathrm{Ag}\left(10.27 \mathrm{~cm}^{3}\right)$. This sulfidationinduced swelling in the silver layer would cause mechanical stress that would crack the protection layer above and cause its detachment at the extreme surface. In turn, the cracks generated in the protection would open new pathways for $\mathrm{H}_{2} \mathrm{~S}$ ingress which could feed further lateral growth of silver sulfide. In the substrate surface region (not shown), the sulfide spots decrease to an average size $\left(45.8 \mu \mathrm{m}^{2}\right)$ comparable to that of the $\mathrm{SiC}$ surface pores measured by AFM. This is consistent with removal of the covering silver layer, except in the surface pores of the substrate where silver has been sulfurized. This reveals that tarnishing also progresses in-depth to degrade all silver locally available.

\section{Conclusions}

Combined surface and interface analysis has been applied to study the local degradation mechanisms by tarnishing of protected silver mirror stacks of space telescopes embarked on satellites and occurring in earth atmosphere before launching. Model stack samples consisting of thin silver layers supported on light-weight SiC substrates and covered by $\mathrm{SiO}_{2}$ coatings deposited by cathodic magnetron sputtering were analyzed by AFM, XPS and ToF-SIMS before and after accelerated aging in $\mathrm{H}_{2} \mathrm{~S}$ gas at 1000 mbar and $75^{\circ} \mathrm{C}$.

The results show that substrate surface pores, resulting from the $\mathrm{SiC}$ material processing, promote the local initiation of tarnishing. Silver sulfide columns, identified as $\mathrm{Ag}_{2} \mathrm{~S}$ by XPS, grow locally with the same density as the $\mathrm{SiC}$ surface pores as a result from an imperfect protection by the $\mathrm{SiO}_{2}$ barrier layer as shown by AFM and ToF-SIMS. It is 
concluded that channels most likely connect the silver layer to the environment through the deposited protection layer, which enables local $\mathrm{H}_{2} \mathrm{~S}$ entry and $\mathrm{Ag}_{2} \mathrm{~S}$ growth as columns until emergence at the stack surface above the protection layer as observed by AFM, ToF-SIMS and XPS. Preferential emergence of sulfide columns observed by AFM above the walls of the $\mathrm{SiC}$ surface pores shows that substrate sites of high aspect are more imperfectly protected after deposition and thus more susceptible to the initiation of tarnishing.

With ongoing aging, the sulfide spots observed by ToF-SIMS grow in number and size eventually leading to coalescence of nearby sulfide columns. In more advanced stages, tarnishing gets slower owing to saturation of all pre-existing defect sites (surface pores) for preferential sulfidation. However, sulfidation still progresses laterally underneath the protection layer, consuming the silver layer and deteriorating the protection layer as revealed by ToF-SIMS depth profile imaging. The mechanical stress induced by volume expansion related to $\mathrm{Ag}_{2} \mathrm{~S}$ formation from metallic silver is thought to crack the covering $\mathrm{SiO}_{2}$ barrier layer, thus opening new pathways for $\mathrm{H}_{2} \mathrm{~S}$ ingress and enabling radial progress of local tarnishing underneath the protection layer.

\section{Acknowledgment}

Region Ile-de-France is acknowledged for partial funding of the ToF-SIMS and XPS equipment.

\section{References}


(1) Bennett J. M.; Ashley E. J. Infrared reflectance and emittance of silver and gold evaporated in ultrahigh vacuum. Appl. Opt. 1965, 4, 221-224.

(2) Thomas N.; Wolfe J. UV-shifted durable silver coating for astronomical mirrors. In Proc. SPIE 4003, Optical Design, Materials, Fabrication, and Maintenance, pp. 312-323, 2000.

(3) Leygraf C.; Wallinder I. O.; Tidblad J.; Graedel T. Atmospheric Corrosion, Second Edition. John Wiley \& Sons, Inc.: Hoboken, USA, 2016.

(4) Pope D.; Gibbens H. R.; Moss R. L. The tarnishing of Ag at naturally-occurring $\mathrm{H}_{2} \mathrm{~S}$ and $\mathrm{SO}_{2}$ levels. Corrosion Sci. 1968, 8, 883-887.

(5) Franey J. P.; Kammlott G. W.; Graedel T. E. The corrosion of silver by atmospheric sulfurous gases. Corrosion Sci. 1985, 25, 133-143.

(6) Graedel T. E. Corrosion mechanisms for silver exposed to the atmosphere. $J$. Electrochem. Soc 1992, 139, 1963-1970.

(7) Kleber C.; Hilfrich U.; Schreiner M. In situ investigations of the interaction of small inorganic acidifying molecules in humidied air with polycrystalline metal surfaces by means of TM-AFM, IRRAS, and QCM. Surf. Interf. Anal. 2007, 39, 702-710.

(8) Price L. E.; Thomas G. J. The tarnishing of silver and silver alloys and its prevention. The Journal of the Institute of Metals 1938, 63, 29-65.

(9) Volpe L.; Peterson P. J. The atmospheric sulfidation of silver in a tubular corrosion reactor. Corrosion Sci. 1989, 29, 1179-1196.

(10) Kleber C.; Wiesinger R.; Schnöller J.; Hilfrich U.; Hutter H.; Schreiner M. Initial oxidation of silver surfaces by $\mathrm{S}^{2+}$ and $\mathrm{S}^{4+}$ species. Corrosion Sci. 2008, 50, 1112-1121.

(11) Junge C. E. Recent investigations in air chemistry. Tellus Ser. A-Dyn. Meteorol. Oceanol. 1956, 8, 127-139.

(12) Abbott W. Mechanism of tarnishing of precious-metal contact alloys. IEEE Transactions on Parts, Materials and Packaging 1969, 5, 156-160.

(13) Watts S. F. The mass budgets of carbonyl sulfide, dimethyl sulfide, carbon disulfide and hydrogen sulfide. Atmos. Environ. 2000, 34, 761-779.

(14) Ankersmit H. A.; Tennent N. H.; Watts S. F. Hydrogen sulfide and carbonyl sulfide in the museum environment - Part 1. Atmos. Environ. 2005, 39, 695-707. 
(15) Watanabe M.; Shinozaki S.; Toyoda E.; Asakura K.; Ichino T.; Kuwaki N.; Higashi Y.; Tanaka T. Corrosion products formed on silver after a one-month exposure to urban atmospheres. Corrosion 2006, 62, 243-250.

(16) Horvath J.; Hackl L. Check of the potential/ph equilibrium diagrams of different metalsulphur-water ternary systems by intermittent galvanostatic polarization method. Corrosion Sci. 1965, 5, 525-538.

(17) Rice D. W.; Cappell R. J.; Kinsolving W.; Laskowski J. J. Indoor corrosion of metals. J. Electrochem. Soc. 1980, 127, 891-901.

(18) Rice D. W.; Cappell R. J.; Phipps P.; Peterson P. Indoor atmospheric corrosion of copper, silver, nickel, cobalt and iron. In: Atmospheric Corrosion (Ailor W. H., ed.). Wiley: New York, pp. 651-666, 1982.

(19) Fukuda Y.; Fukushima T.; Sulaiman A.; Musalam I.; Yap L. C.; Chotimongkol L.; Judabong S.; Potjanart A.; Keowkangwal O.; Yoshihara K.; Tosa M. Indoor corrosion of copper and silver exposed in japan and ASEAN1 countries. J. Electrochem. Soc. 1991, $138,1238-1243$.

(20) Bouquet S.; Bodin C.; Fiaud C. Relative influence of sulfide and chloride compounds on tarnishing of silver in atmospheric corrosion. CR. Acad. Sci. II 1993, 316, 459-464.

(21) Dowsett M. G.; Adriaens A.; Soares M.; Wouters H.; Palitsin V. V. N.; Gibbons R.; Morris R. J. H. The use of ultra-low-energy dynamic SIMS in the study of the tarnishing of silver. Nuclear Instruments and Methods in Physics Research Section B: Beam Interactions with Materials and Atoms 2005, 239, 51-64.

(22) Liang D.; Allen H. C.; Frankel G. S.; Chen Z. Y.; Kelly R. G.; Wu Y.; Wyslouzil B. E. Effects of sodium chloride particles, ozone, uv, and relative humidity on atmospheric corrosion of silver. J. Electrochem. Soc. 2010, 157, C146-C156.

(23) Rice D. W.; Peterson P.; Rigby E. B.; Phipps P. B. P.; Cappell R. J.; Tremoureux R. Atmospheric corrosion of copper and silver. J. Electrochem. Soc. 1981, 128, 275-284.

(24) Lilienfeld S. White C. E. A study of the reaction between hydrogen sulfide and silver. $J$. Am. Chem. Soc. 1930, 52, 885-892.

(25) Burge D. K.; Bennett H. E.; Ashley E. J. Effect of atmospheric exposure on the infrared reflectance of silvered mirrors with and without protective coatings. Appl. Opt. 1973, 12, $42-47$. 
(26) Kasukabe S. Growth mechanism and growth form of Beta- $\mathrm{Ag}_{2} \mathrm{~S}$ whiskers. J. Cryst. Growth 1983, 65, 384-390.

(27) Graedel T. E.; Franey J. P.; Gualtieri G. J.; Kammlott G. W.; Malm D. L. On the mechanism of silver and copper sulfidation by atmospheric $\mathrm{H}_{2} \mathrm{~S}$ and OCS. Corrosion Sci. 1985, 25, 1163-1180.

(28) Hass G. Reflectance and preparation of front-surface mirrors for use at various angles of incidence from the ultraviolet to the far infrared. J. Opt. Soc. Am. 1982, 72, 27-39.

(29) Waterhouse G. I. N.; Bowmaker G. A.; Metson J. B. Oxidation of a polycrystalline silver foil by reaction with ozone, Appl. Surf. Sci. 2001, 183, 191-204.

(30) Bennett J. M.; Stanford J. L.; Ashley E. J. Optical constants of silver sulfide tarnish films, J. Opt. Soc. Am. 1970, 60, 224-231.

(31) Phillips A. C.; Miller J.; Brown W.; Hilyard D.; Dupraw B.; Wallace V.; Cowley D. Progress toward high-performance reflective and anti-reflection coatings for astronomical optics. In Proc. SPIE 7018, Advanced Optical and Mechanical Technologies in Telescopes and Instrumentation, 70185A, 2008.

(32) Wolfe J. D.; Laird R. E.; Carniglia C. K. Durable silver-based antireflection coatings and enhanced mirrors. In: Optical Interference Coatings, Vol. 17, OSA Technical Digest Series (Optical Society of America), pp. 115-117, 1995.

(33) Wolfe J. D.; Sanders D. M.; Bryan S.; Thomas N. L. Deposition of durable wide-band silver mirror coatings using long-throw, low-pressure, DC-pulsed magnetron sputtering. In Proc. of SPIE: Astronomical Telescopes and Instrumentation: Specialized optical developments in astronomy, The International Society for Optics and Photonics, pp. 343$351,2003$.

(34) Sheikh D. A.; Connell S. J.; Dummer R. S. Durable silver coating for Kepler space telescope primary mirror. In Proc. SPIE 7010, Space Telescopes and Instrumentation 2008: Optical, Infrared, and Millimeter, 70104E, 2008.

(35) Fuqua P. D.; Barrie J. D.; Optical properties and corrosion resistance of durable silver coatings. Mat. Res. Soc. Symp. Proc. 1998, 555, 85-90.

(36) Chu C.-T.; Chaffee P. D.; Panetta C. J.; Fuqua P. D.; Barrie J. D. Mixed flowing gas testing of silver mirror coatings. In: OSA Technical Digest (CD), Optical Interference Coatings, paper TuEPDP5, 2007. 
(37) Feller A.; Nagaraju K.; Pleier O.; Hirzberger J.; Jobst P. J.; Schuermann M. Reflectivity, polarization properties and durability of metallic mirror coatings for the european solar telescope. In: Proc. SPIE 8450, Modern Technologies in Space- and Ground-based Telescopes and Instrumentation II, 84503U, 2012.

(38) Pellicori S. F. Scattering defects in silver mirror coatings. Appl. Opt. 1980, 19, 30963098.

(39) Chu, C.-T.; Fuqua P. D.; Barrie J. D., Corrosion characterization of durable silver coatings by electrochemical impedance spectroscopy and accelerated environmental testing. Appl. Opt. 2006, 45, 1583-1593.

(40) Folgner, K. A.; Chu, C.-T.; Lingley, Z.R.; Kim, H. I.; Yang, J.-M.; Barrie J. D. Environmental durability of protected silver mirrors prepared by plasma beam sputtering. Appl. Opt. 2017, 56, C75-C86.

(41) Chauveau G.; Torricini D.; Grèzes-Besset C.; Stojcevski D. Lequime M. PACA2M: magnetron sputtering for 2-meter optics. In Proc. SPIE 8168, Advances in Optical Thin Films IV, 81680P, 2011.

(42) Lequime M.; Grezes-Besset C.; Chauveau G.; Stojcevski D. Optimization of the manufacturing strategies of high quality coatings into a 2-meter optics magnetron sputtering deposition machine. In 2014 Technical Conference Proceedings, Optical Coatings (September 29, 2014) TechCon2014, Society of Vacuum Coaters, 2014.

(43) Valette N.; Chauveau G.; Grèzes-Besset C.; Costes V.; Savin de Larclause I.; Gasc K.; Lemarquis F. PACA2M magnetron sputtering silver coating: a solution for very big mirror dimensions, In ICSO 2014 Proceedings, International Conference on Space Optics, Tenerife, Canary Islands, Spain, 7 - 10 October 2014.

(44) Bénard J.; Oudar J.; Cabané-Brouty F. Contribution á l'étude de l'adsorption chimique réversible du soufre sur l'argent. Surf. Sci. 1965, 3, 359-372.

(45) Lindström R.; Maurice V.; Groult H.; Perrigaud L.; Zanna S.; Cohen C.; Marcus P. Liintercalation behaviour of vanadium oxide thin film prepared by thermal oxidation of vanadium metal. Electrochim. Acta 2006, 51, 5001-5011.

(46) Liao F.; Światowska J.; Maurice V.; Seyeux A.; Klein L. H.; Zanna S.; Marcus P. Electrochemical lithiation and passivation mechanisms of iron monosulfide thin film as negative electrode material for lithium-ion batteries studied by surface analytical techniques. App. Surf. Sci. 2013, 283, 888-899. 
(47) Tian B.; Światowska J.; Maurice V.; Zanna S.; Seyeux A.; Klein L. H.; Marcus P. Combined surface and electrochemical study of the lithiation/delithiation mechanism of the iron oxide thin-film anode for lithium-ion batteries. J. Phys. Chem. C 2013, 117, 21651-21661.

(48) Tanuma, S.; Powell, C. J.; Penn, D. R. Calculations of electron inelastic mean free paths. Surf. Interface Anal. 1993, 21, 165-176.

(49) Chiba K.; Nakatani K. Photoenhanced migration of silver atoms in transparent heat mirror coatings. Thin Solid Films 1984, 112, 359-367.

(50) Jacobson M. R.; Kneale R. C.; Gillett F. C.; Raybould K.; Filhaber J. F.; Carniglia C. K.; Laird R.; Kitchens D.; Shimshock R. P.; Booth D. C. Development of silver coating options for the Gemini 8-m telescopes project. In: Proc. SPIE 3352, Advanced Technology Optical/IR Telescopes VI, pp. 477-502, 1998.

(51) Ben Amor Y.; Sutter E. M.; Takenouti H.; Orazem M. E.; Tribollet B. Interpretation of electrochemical impedance for corrosion of a coated silver film in terms of a pore-inpore model. J. Electrochem. Soc. 2014, 161, C573-C579.

(52) Ross R. C.; Sherman R.; Bunger R. A.; Nadel S. J. Plasma oxidation of silver and zinc in low-emissivity stacks. Sol. Energy Mater. 1989, 19, 55-65.

(53) Díaz B.; Härkönen E.; Światowska J.; Maurice V.; Seyeux A.; Marcus P.; Ritala M. Low-temperature atomic layer deposition of $\mathrm{Al}_{2} \mathrm{O}_{3}$ thin coatings for corrosion protection of steel: Surface and electrochemical analysis. Corrosion Sci. 2011, 53, 2168-2175.

(54) Díaz B.; Światowska J.; Maurice V.; Pisarek M.; Seyeux A.; Zanna S.; Tervakangas S.; Kolehmainen J.; Marcus P. Chromium and tantalum oxide nanocoatings prepared by filtered cathodic arc deposition for corrosion protection of carbon steel. Surf. Coat. Technol. 2012, 206, 3903-3910.

(55) Díaz B.; Światowska J.; Maurice V.; Seyeux A.; Zanna S.; Härkönen E.; Ritala M.; Tervakangas S.; Kolehmainen J.; Marcus P. Tantalum oxide nanocoatings prepared by atomic layer and filtered cathodic arc deposition for corrosion protection of steel: Comparative surface and electrochemical analysis. Electrochim. Acta 2013, 90, 232245.

(56) Díaz B.; Światowska J.; Maurice V.; Seyeux A.; Normand B.; Härkönen E.; Ritala M.; Marcus P. Electrochemical and time-of-flight secondary ion mass spectrometry analysis 
of ultra-thin metal oxide $\left(\mathrm{Al}_{2} \mathrm{O}_{3}\right.$ and $\left.\mathrm{Ta}_{2} \mathrm{O}_{5}\right)$ coatings deposited by atomic layer deposition on stainless steel. Electrochim. Acta 2011, 56, 10516- 10523.

(57) Mirhashemihaghighi S.; Światowska J.; Maurice V.; Seyeux A.; Klein L. H.; Härkönen E.; Ritala M.; Marcus P. Electrochemical and surface analysis of the corrosion protection of copper by nanometer-thick alumina coatings prepared by atomic layer deposition, $J$. Electrochem. Soc. 2015, 162, C377-C384.

(58) Mirhashemihaghighi S.; Światowska J.; Maurice V.; Seyeux A.; Klein L. H.; Härkönen E.; Ritala M.; Marcus P. Interfacial native oxide effects on the corrosion protection of copper coated with ALD alumina. Electrochim. Acta 2016, 193, 7-15.

(59) Newns G. R.; Pantelis P.; Wilson J. L.; J. Uffen R. W.; Worthington R. Absorption losses in glasses and glass fibre waveguides. Opto-electron. 1973, 5, 289-296.

(60) Schultz P. C. Optical Absorption of the Transition Elements in Vitreous Silica. J. Am. Ceram. Soc. 1974, 57, 309-313.

(61) Kaiser N. Review of the fundamentals of thin-film growth. Appl. Opt. 2002, 41, 30533060, 2002.

(62) Miller M. L.; Linton R. W. X-ray photoelectron spectroscopy of thermally treated silica $\left(\mathrm{SiO}_{2}\right)$ surfaces. Anal. Chem. 1985, 57, 2314-2319.

(63) Jeong S.-H.; Kim J.-K.; Kim B.-S.; Shim S.-H.; Lee B.-T. Characterization of $\mathrm{SiO}_{2}$ and $\mathrm{TiO}_{2}$ films prepared using rf magnetron sputtering and their application to anti-reflection coating. Vacuum 2004, 76, 507-515.

(64) Kaushik V. K. XPS core level spectra and auger parameters for some silver compounds, J. Electron Spectrosc. Relat. Phenom. 1991, 56, 273-277.

(65) Turner N. H.; Murday J. S.; Ramaker D. E. Quantitative determination of surface composition of sulfur bearing anion mixtures by Auger electron spectroscopy. Anal. Chem. 1980, 52, 84-92.

(66) Scaini M. J.; Bancroft G. M.; Lorimer J.W.; Maddox L. M. The interaction of aqueous silver species with sulphur-containing minerals as studied by XPS, AES, SEM, and electrochemistry. Geochim. Cosmochim. Acta, 1995, 59, 2733-2747.

(67) $\mathrm{Kim} \mathrm{H}$. Corrosion process of silver in environments containing $0.1 \mathrm{ppm}_{2} \mathrm{~S}$ and 1.2 ppm $\mathrm{NO}_{2}$, Mater. Corros. 2003, 54, 243-250.

(68) Wagner C. D.; Joshi A. The Auger parameter, its utility and advantages: a review. J. Electron Spectrosc. Relat. Phenom. 1988, 47, 283-313. 
(69) Zhang W.; Zhang L.; Hui Z.; Zhang X. Qian Y. Synthesis of nanocrystalline $\operatorname{Ag}_{2} \mathrm{~S}$ in aqueous solution. Solid State Ion. 2000, 130, 111-114.

(70) Doriot-Werle M.; Banakh O.; Gay P.; Matthey J.; Steinmann P. Tarnishing resistance of silver-palladium thin films. Surf. Coat. Technol. 2006, 200, 6696-6701.

(71) Krylova V.; Baltrusaitis J. Synthesis and properties of polyamide- $\mathrm{Ag}_{2} \mathrm{~S}$ composite based solar energy absorber surfaces. Appl. Surf. Sci. 2013, 282, 552-560.

(72) Bennett H. E.; Peck R. L.; Burge D. K.; Bennett J. M. Formation and growth of tarnish on evaporated silver films. J. Appl. Phys. 1969, 40, 3351-3360. 


\section{Figure captions}

Figure 1 (color online) AFM topographic images of the SiC substrate surface as-received $(a, b, c)$ and after $(d, e, f)$ deposition of the silver mirror layer by cathodic magnetron sputtering. Color-coded $\Delta z$ range is $150 \mathrm{~nm}(a), 20 \mathrm{~nm}(b, d, e), 130 \mathrm{~nm}(c)$ and $300 \mathrm{~nm}(f)$.

Figure 2 (color online) ToF-SIMS elemental depth profiles of the complete multilayer stack consisting of the silver mirror layer deposited on the NiCr layer grown on the SiC substrate and covered by the silicon oxide protection layer with an interface layer. Selected negative secondary ions are marked.

Figure 3 (color online) XP spectra of Ag3d and S2p core levels for complete stacks prior to (O h) and after 24, 48 and 96 h accelerated aging in $\mathrm{H}_{2} \mathrm{~S}$ at 1000 mbar and $75^{\circ} \mathrm{C}$.

Figure 4 (color online) AFM topographic images for complete stacks prior to (a) and after (b,c) 24 h accelerated aging in $\mathrm{H}_{2} \mathrm{~S}$ at 1000 mbar and $75^{\circ} \mathrm{C}$. Color-coded $\Delta z$ range is $100 \mathrm{~nm}$ (a), $1000 \mathrm{~nm}(b)$ and $400 \mathrm{~nm}(c) .(c)$ is an enlarged image of the local region marked in (b).

Figure 5 (color online) ToF-SIMS elemental images of $O^{-}, S^{-}$and $O^{-}+S^{-}$ions for complete stacks after 24, 48 and $96 \mathrm{~h}$ accelerated aging in $\mathrm{H}_{2} \mathrm{~S}$ at $1000 \mathrm{mbar}$ and $75^{\circ} \mathrm{C}$. In the superimposed $\mathrm{O}^{-}+\mathrm{S}^{-}$image, $\mathrm{O}^{-}$and $\mathrm{S}^{-}$ions are coded in green and red, respectively.

Figure 6 (color online) ToF-SIMS depth profiles of the $\mathrm{SiO}^{-}, \mathrm{AgS}^{-}$and ${ }^{34} \mathrm{~S}^{-}$ions for complete stacks prior to $(\mathrm{O} h)$ and after 24, 48 and $96 \mathrm{~h}$ accelerated aging in $\mathrm{H}_{2} \mathrm{~S}$ at $1000 \mathrm{mbar}$ and $75^{\circ} \mathrm{C}$

Figure 7 (color online) ToF-SIMS sequential in-depth elemental images of $\mathrm{O}^{-}+\mathrm{S}^{-}+\mathrm{Ag}^{-}$ions for the complete stack after $96 \mathrm{~h}$ accelerated aging in $\mathrm{H}_{2} \mathrm{~S}$ at $1000 \mathrm{mbar}$ and $75^{\circ} \mathrm{C}$, (a) outer 
surface, (b) silicon oxide protection layer, (c) silver mirror layer. The $\mathrm{O}^{-}, \mathrm{S}^{-}$and $\mathrm{Ag}^{-}$ions images are coded in green, red and blue, respectively. 
Figure 1
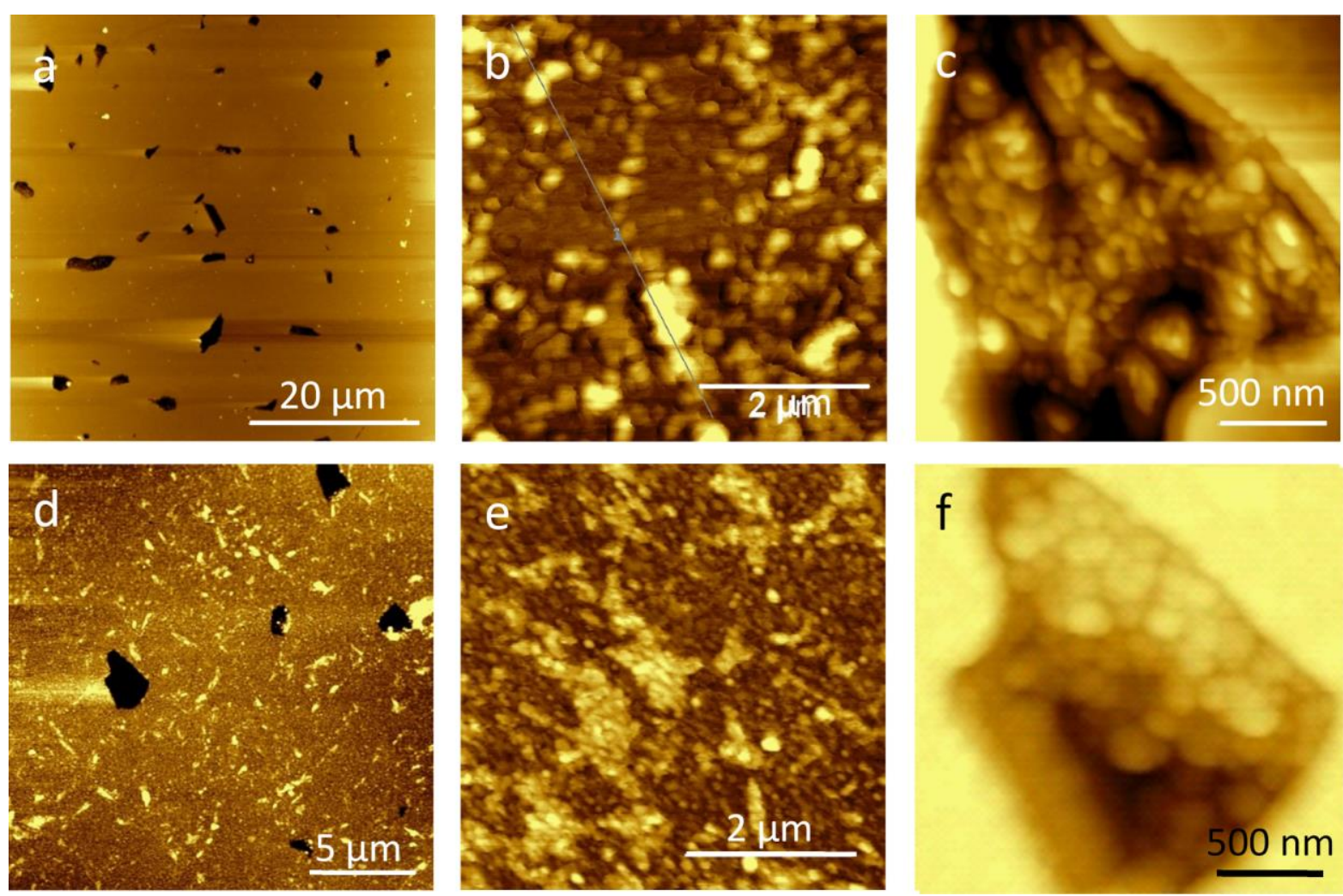
Figure 2

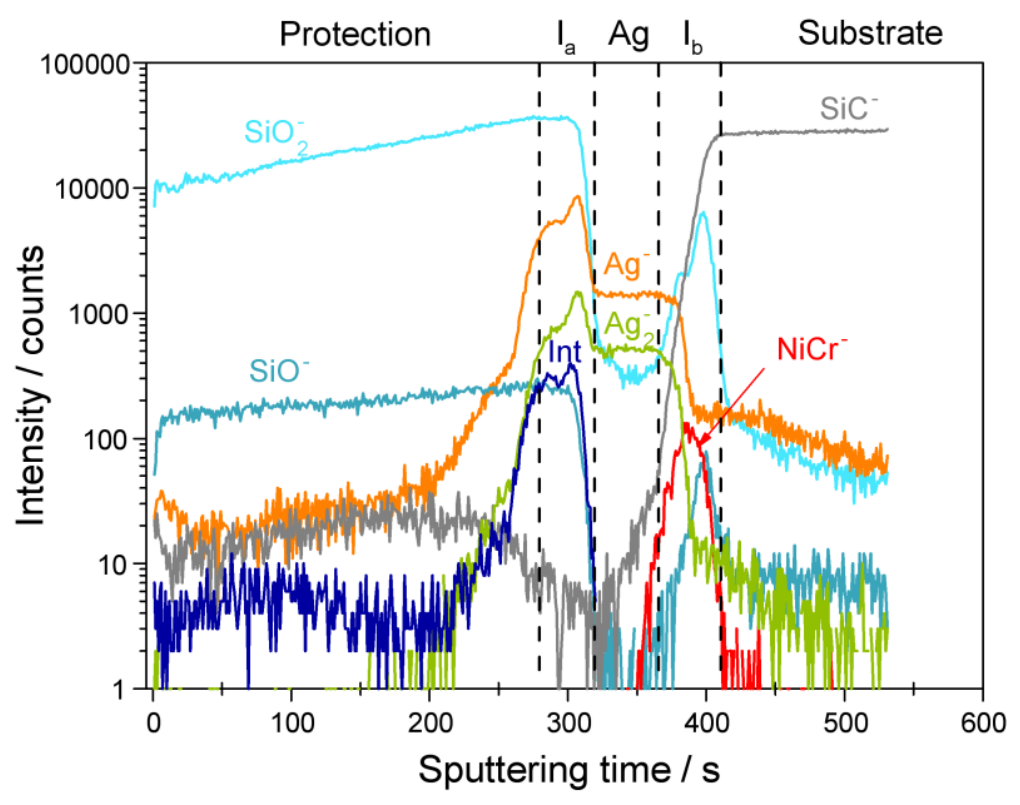


Figure 3
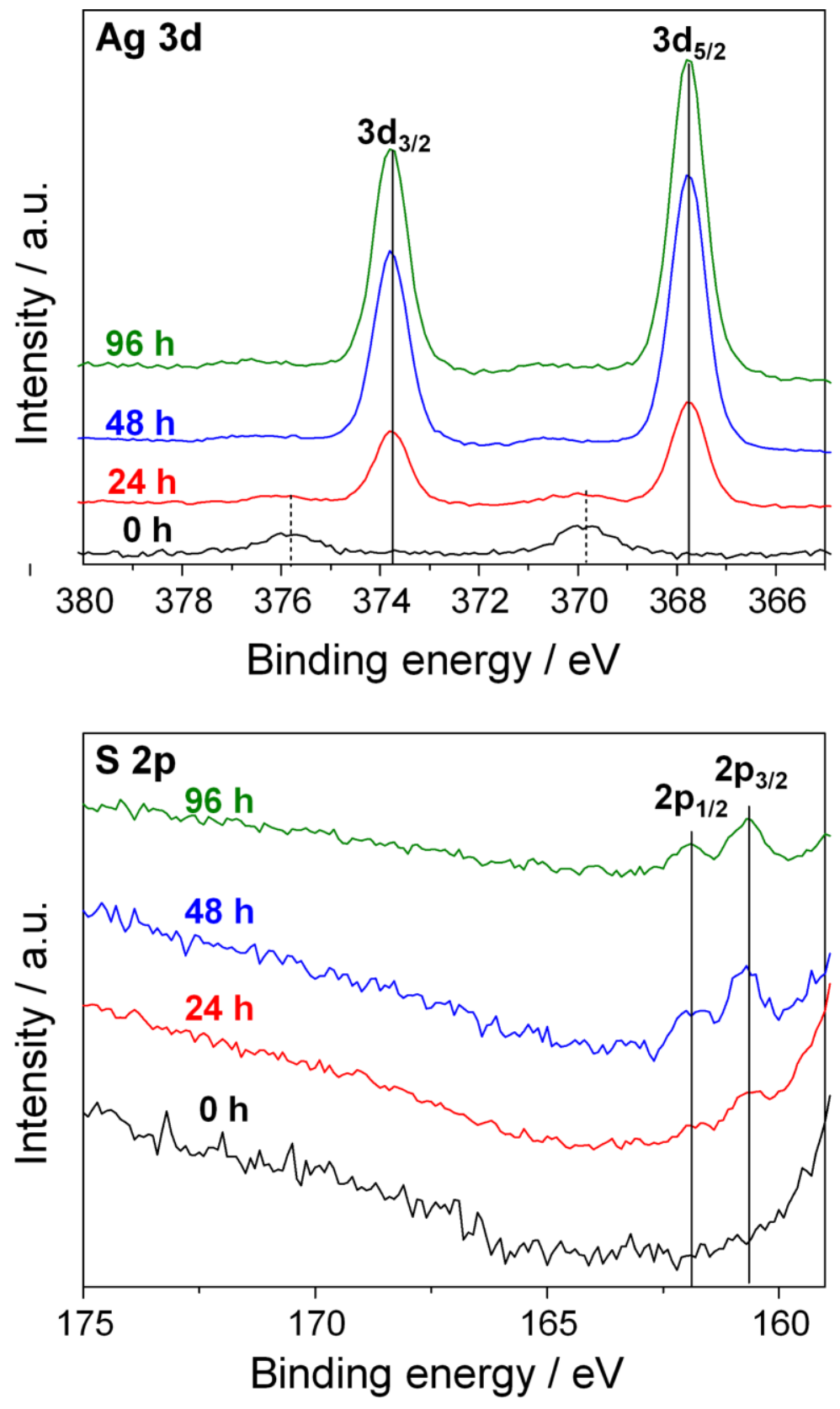
Figure 4
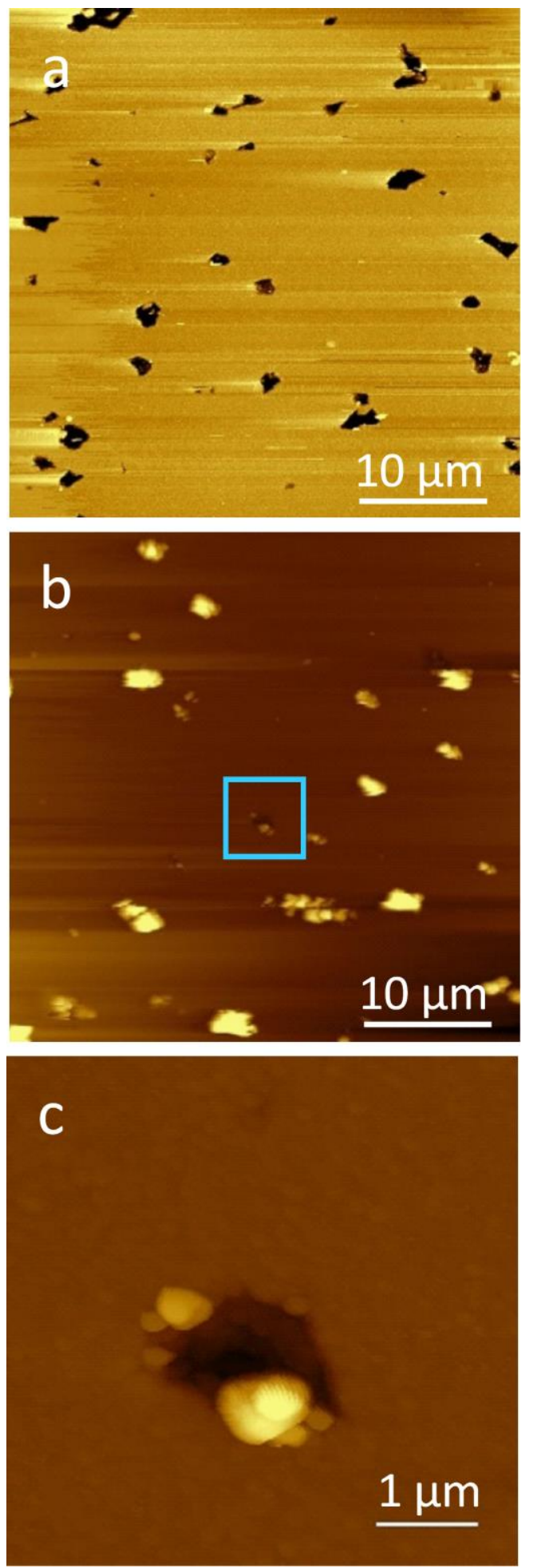
Figure 5
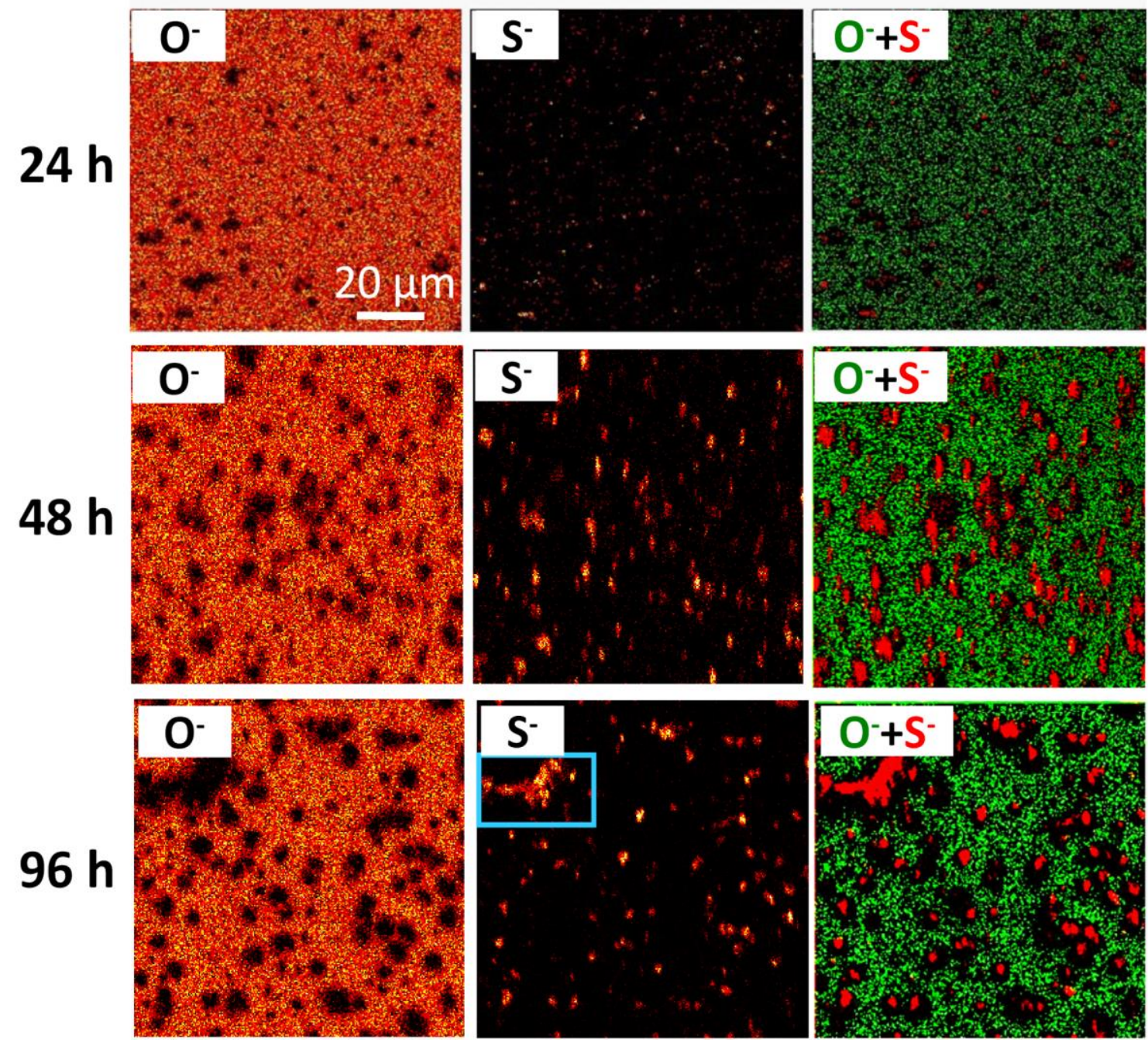
Figure 6
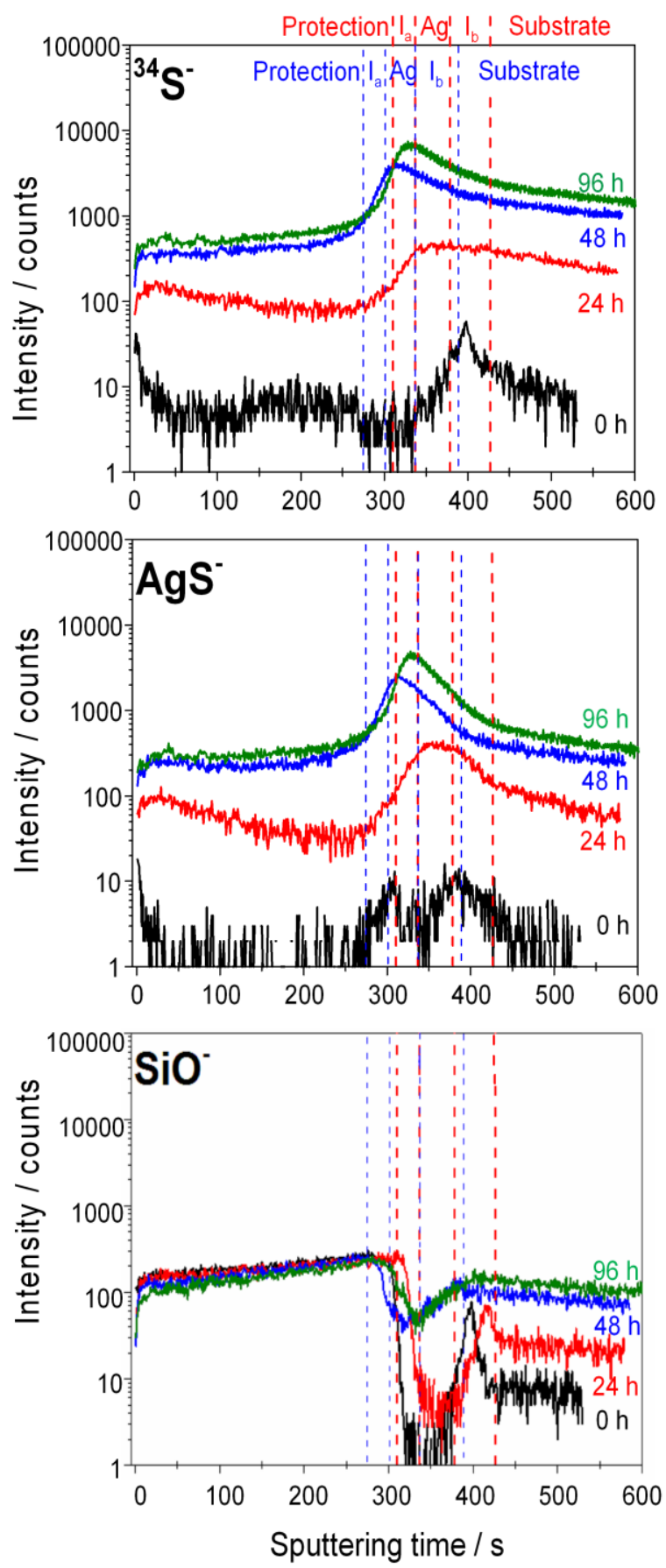
Figure 7

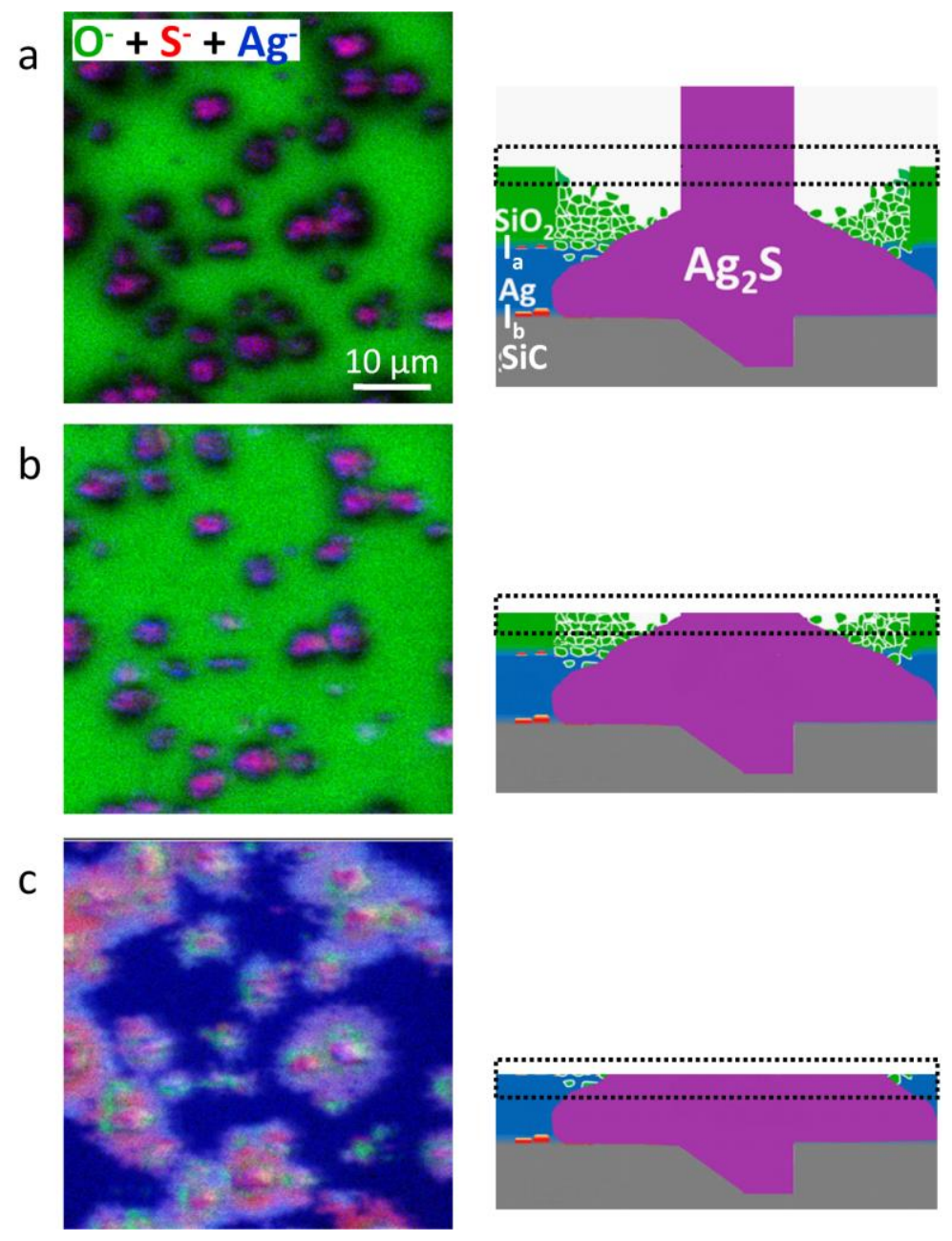


TOC Graphic

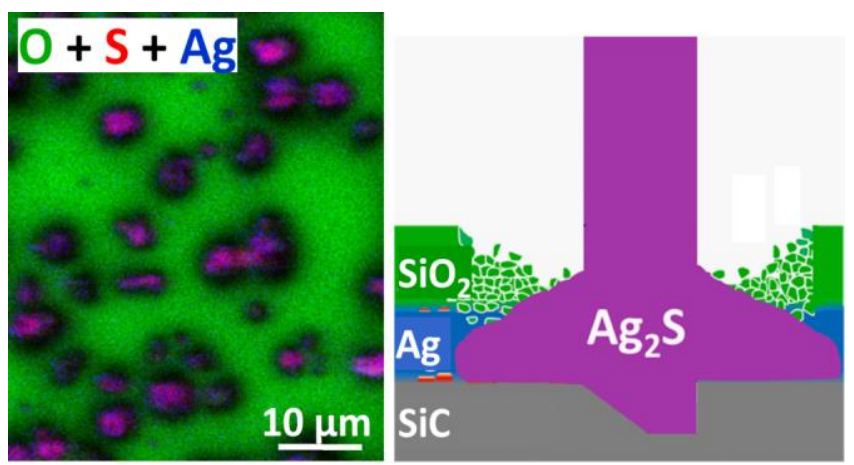

